\title{
Inequities and perspectives from the COVID-Delta outbreak: The imperative for strengthening the Pacific nursing workforce in Aotearoa New Zealand
}

Abel Smith1,5, MPP(Leadership), RN, Director of Nursing Pacific

Safaato'a (To'a) Fereti ${ }^{2,3}, \mathrm{MN}$ RN, Chief Clinical Advisor Pacific; President - Pan Pacific Nurses Association

Sue Adams ${ }^{4}$, PhD RN, Senior Lecturer/Co-Leader National Nurse Practitioner \& Enrolled Nurse Workforce Programme, School of Nursing

${ }^{1}$ Auckland District Health Board, Aotearoa New Zealand

2Ministry of Heath, Aotearoa New Zealand

${ }^{3}$ Auckland, Aotearoa New Zealand

${ }^{4}$ University of Auckland, Aotearoa New Zealand

5Corresponding Author: AbelS@adhb.govt.nz; s.adams@auckland.ac.nz

\section{Citation}

Smith, A., Fereti, S., \& Adams, S. (2021). Inequities and perspectives from the COVID-Delta outbreak: The imperative for strengthening the Pacific nursing workforce in Aotearoa New Zealand. Nursing Praxis in Aotearoa New Zealand, 37(3), 94-103.

https://doi.org.10.36951/27034542.2021.040

\begin{abstract}
The COVID-19 Delta August 2021 outbreak in Aotearoa New Zealand initially affected Pacific communities more than any other group, spreading later and rapidly to Māori. From the outset of the global pandemic, historical knowledge of health inequities and the adverse effect of previous epidemics and pandemics, signaled that Pacific peoples, and Māori, would be disproportionately affected by COVID-19. The purpose of this article is to provide an overview of the COVID-19 pandemic in relation to Pacific communities and to begin to capture the learnings for the health system and the Pacific nursing workforce. We use data to show the inequities present before and during the pandemic and highlight the opportunities that were missed early on for prioritising Pacific communities. As nurse leaders, involved with supporting and promoting the Pacific nursing workforce, we reflect on the nursing response to COVID-19 in those Pacific communities, and consider the contribution of Pacific nurses and how we support and strengthen the Pacific nursing workforce in Aotearoa now and in the future.
\end{abstract}

Keywords / Ngā kupu matua: community / hapori; COVID-19; dialogue / whakawhiti kōrero; inequities / ngā korenga e ōrite; nursing / mahi tapuhi; Pacific / Moana-nui-a-Kiwa; primary health care / taurimatanga hauora tuatahi

\section{Te Reo Māori translation}

He korenga e ōrite me ngā kitenga mai i te horapatanga o te mate urutā o COVID-Delta: Te whakahau kia whakapakaritia te ohu kaimahi tapuhi Moana-nui-a-Kiwa i Aotearoa

\section{Ngā ariā matua}

I tino pā nui te horapatanga mate urutā COVID-19 i Aotearoa ki ngā hapori Moana-nui-a-Kiwa, he kaha kē atu i te pānga ki ētahi atu momo iwi, à, nō muri mai ka horapa nui, ka tere horapa hoki ki a ngāi Māori. Mai i te tīmatanga o te mate urutā o te ao, nā te mātauranga mō ngā korenga e ōrite o ngā āhuatanga hauora nui, kua ara ake ngā matapae tērā pea ka kaha ake te mate rawa me te pā nui hoki o ngā raru hauora ki ngā iwi o Te Moana-nui-a-Kiwa me ngā iwi Māori. Ko te whāinga o tēnei tuhinga he whakarāpopoto i te pānga o te urutā o COVID-19 ki ngā hapori o Te Moana-nui-a-Kiwa, kia hopukina hoki ngā akoranga mō te pūnaha hauora me te ohu kaimahi tapuhi Moana-nui-a-Kiwa. Ka whakamahi raraunga mātou kia kitea ngā kōrenga e ōrite o mua, i waenga hoki i te mate urutā, kia whakatairangatia hoki ngā whāinga wāhi kāore i tutuki mō ngā hapori Moana-nui-a-Kiwa He kaihautū tapuhi mātou e tautoko ana, e whakatairanga ana i te ohu kaimahi tapuhi Moana-nui-a-Kiwa, ā, ko mātou tēnei e huritao nei mō te urupare tapuhi ki te COVID-19 i roto i aua hapori Moana-nui-a-Kiwa, me te huritao i te āwhina o ngā tapuhi Moana-nui-a-Kiwa, me pēhea hoki tā tātou tautoko, whakapakari hoki i te ohu tapuhi Moana-nui-a-Kiwa i tēnei rā, ā, haere ake nei. 


\section{Introduction}

Globally, COVID-19 has disproportionately and adversely affected the health and wellbeing of population groups already vulnerable and marginalised in society - Indigenous, Black, poor those who experience inequities in health outcomes and access to quality health services (Evans, 2020). Institutional racism remains across our systems of governance and state control (Health \& Disability System Review, 2020). The expectation from the outset was that Māori and Pacific would experience inequitable outcomes and more significant long-term consequences (Ministry of Health, 2020a), based upon contemporary and historical knowledge of poor health outcomes, persisting health and social inequities, and previous pandemics (Steyn et al., 2021; Wilson et al, 2012). The devastating effects of the 2019 measles epidemic in Samoa showed how the spread of myths and misinformation through social media together with the rise of anti-vaxxers and delayed Government response, compounded actions to protect the communities (Boodoosingh et al., 2020). Despite the warnings, 18 months into the pandemic, a COVID-19 Delta community outbreak in August 2021 (the Delta outbreak) has resulted in 818 (65\%) of all new positive cases being Pacific (Ministry of Health, 2021, 30 Sept).

This article is intended as the beginning of a much wider conversation to explore the role that Pacific nurses have played to ensure the safety, protection, and wellbeing of their Pacific communities. Through the COVID-19 pandemic Pacific nurses have worked at testing stations, contact tracing centers, vaccination centres, managed isolation facilities (MIQ), health helplines as well as continuing their everyday work in hospitals and the community. The collective worldview of Pacific peoples means that family and community is prioritised over the individual (Ioane et al., 2021). As such, Pacific nurses not only fulfil their nursing role, but under the principles of respect, reciprocity, and collectivism, undertake a range of other support and caring work within their communities. Yet Pacific nurses are underrepresented being only $4 \%$ of the nursing workforce compared to Pacific peoples comprising $7.4 \%$ of the population in Aotearoa (Nursing Council of New Zealand, 2019). The toll of this pandemic on the Pacific nursing workforce, we believe, is considerable.

\section{Approach}

This article begins with a brief introduction to the Pacific peoples of Aotearoa and the Pacific nursing workforce. We provide an overview of the COVID-19 pandemic in relation to Pacific communities, with a particular focus on the August 2021 Delta outbreak and the evident inequities. The data point is taken as 30 September 2021 when Auckland was in its $7^{\text {th }}$ week of Level 3 lockdown (having had four weeks at Level 4), and the remainder of the country was at Level 2.

We then share a conversation, from a nursing leadership position, reflecting on Pacific nurses' involvement in the pandemic. We draw on the concept of talanoa as a research framework that affirms Pacific thinking, language, and culture; challenges Eurocentric institutional systems; and enables the co-creation of knowledge (Matapo \& Enari, 2021). We intend this conversation to open-up lively talanoa within the health and education sector. We argue that this pandemic has shown the imperative that now, more than ever, we need to value, support, invest in, and grow the Pacific nursing workforce, if we are going to address inequities and improve health outcomes for the Pacific peoples of Aotearoa.

\section{Pacific peoples in Auckland}

Pacific Peoples are a diverse population made up of distinct cultures from various Pacific Islands. In Auckland, the Pacific population is mostly New Zealand born, predominantly young, and highly urbanised (StatsNZ, 2018). 16\% of the Auckland population are Pacific, however, the Pacific nursing workforce in Auckland is just $8.6 \%$ of the total nursing workforce (Nursing Council of New Zealand, 2019 ), with only $5.2 \%$ working in primary health care settings. Table 1 shows the Pacific ethnic groups of the Auckland population and the Pacific nursing workforce.

As collective communities, Pacific peoples tend to live as communal and intergenerational family groups and often across several sites or homes. Pacific communities are connected through faith-based networks where church gatherings and services are central to family support and well-being. Church ministers, pastors, and Pacific community leaders are highly influential in directingtheir communities in all matters, including how to respond to COVID-19 (Ministry for Pacific Peoples, 2021). Pacific 
knowledge and cultural protocols are forefront and contrast dominant western worldviews (Ioane et al., 2020).

Table 1: Pacific people living in Auckland and Pacific nurses working in Auckland by Pacific group (StatsNZ, 2018; Nursing Council of New Zealand, 2019).

\begin{tabular}{l|l|l}
\hline & $\begin{array}{l}\text { Auckland Pacific } \\
\text { groups (\%)* }\end{array}$ & $\begin{array}{l}\text { Pacific nurses } \\
\text { in Auckland } \\
(\%)\end{array}$ \\
\hline Samoan & $118,503(48.6 \%)$ & $341(26.3 \%)$ \\
\hline Tongan & $62,403(25.6 \%)$ & $242(18.7 \%)$ \\
\hline $\begin{array}{l}\text { Cook Island } \\
\text { Māori }\end{array}$ & $46,668(19.1 \%)$ & $99(7.6 \%)$ \\
\hline Niuean & $23,088(9.5 \%)$ & $78(6 \%)$ \\
\hline Fijian & $11,202(4.6 \%)$ & $448(34.5 \%)$ \\
\hline Tokelauan & $2,406(1 \%)$ & $18(1.4 \%)$ \\
\hline $\begin{array}{l}\text { Other Pacific } \\
\text { Peoples }\end{array}$ & $7,485(3.1 \%)$ & $71(5.6 \%)$ \\
\hline T0TAL & $\mathbf{2 4 3 , 9 6 6}$ & $\mathbf{1 2 9 7}$ \\
\hline
\end{tabular}

*Percentages add to more than $100 \%$. When a person reported more than one Pacific ethnic group they were recorded in both. Ethnicity is prioritised as follows: Māori; Pacific; Asian; Middle Eastern, Latin American and African; NZ European/Other

During the 1950s and 60s, immigration of Pacific peoples to Aotearoa New Zealand increased considerably to fulfil a labour crisis. However, an economic recession in the 1970s saw high unemployment, with Pacific peoples the subject of discriminatory and racist governmental and police initiatives to limit immigration and forcibly remove overstayers (Ardern, 2021). On 1 August 2021, the Government issued an apology for what has become known as the Dawn Raids era. Ardern stated, "inequities that stem from direct and indirect discrimination continue to exist" and "lives on in the disruption of trust and faith in authorities" (Ardern, 2021, para $6 \& 7$ ).
Prior to the start of the pandemic, Pacific communities were at social, educational, environmental and economic risk (Ioane, et al., 2021). Many Pacific people live in socio-economic hardship. Across the greater Auckland region, which is divided into three district health board (DHB) areas, each DHB has its own distinct population demographics and deprivation. Counties Manukau DHB covers South Auckland and has the largest Pacific population (Table 2). It also has proportionally more Pacific people who are the most socio-economically deprived with $74 \%$ living in quintile five (Ministry of Health, 2021, a). The compounding effects of material deprivation associated with living in poorer neighbourhoods, with fewer health, educational, and social resources, and greater likelihood of environmental harms, leads to poorer health and social outcomes (Health Quality \& Safety Commission [HQSC], 2021; Walsh \& Gray, 2017).

\section{Pacific peoples and COVID-19}

The first COVID-19 case reached the shores of Aotearoa New Zealand on 28 February 2020. From then until the August 2021 Delta outbreak began, a total of 2987 COVID-19 positive cases had been identified, of which 213 (7\%) were Pacific. A cluster outbreak in August 2020 had a higher proportion of Pacific (62\%) and Māori (21\%) (Sadler, 2020) and affected a younger age group than the first outbreak (Steyn et al., 2021). Four deaths occurred. The learnings from the August 2020 cluster were clear that both Pacific and Māori communities fare worse and need to be prioritised for protection strategies and vaccination. Yet, despite these early warnings, the burden of the August 2021 Delta outbreak has been experienced by Pacific communities in the Auckland area.

Table 2: Population of Auckland DHBs, Pacific population and percentage of Pacific population living in quintile 5.

\begin{tabular}{llll}
\hline DHB & $\begin{array}{l}\text { Total } \\
\text { population } \\
\text { (Projected 2020/21) }\end{array}$ & $\begin{array}{l}\text { Pacific population } \\
(\%)\end{array}$ & $\begin{array}{l}\% \text { of Pacific people } \\
\text { in quintile 5 }\end{array}$ \\
\hline Counties Manukau & 578,650 & $125,240(22 \%)$ & $74 \%$ \\
\hline Auckland & 493,990 & $55,800(11 \%)$ & $45 \%$ \\
\hline Waitematā & 628,770 & $45,200(7.2 \%)$ & $22 \%$ \\
\hline
\end{tabular}

Data from: Auckland DHB, 2020; Lees et al., 2021; Ministry of Health, 2021a; Waitematā DHB, 2019 
The first case in the Delta outbreak was announced on 17 Aug 2021 and by 30 Sept 2021, 1249 positive COVID-19 Delta cases had been identified, of which 818 (65\%) were Pacific (Figure 1) (Ministry of Health, 2021b). While the Delta outbreak began with cases and their contacts within the Waitematā DHB area, in people of New Zealand/European ethnicity, the Delta virus soon spread across the Auckland DHBs and through the Pacific communities. Racism was evident as a Samoan church, at the centre of one of the clusters, experienced racist remarks through social media (Corlett \& McClure, 2021). By 30 September 2021, 785 (63\%) cases resided in Counties Manukau; 219 (17\%) in Auckland; and 228 $(18 \%)$ in Waitematā. Just 17 cases were reported in Wellington.

At the start of the Delta outbreak, Pacific vaccination rates were $12-14 \%$ lower than for non-Māori/non-
Pacific (Ministry of Health, 2021b) (Figure 2). Data released on 8 September by the Ministry of Health showed that of the 855 positive cases, 701 (82\%) were unvaccinated (Cheng, 2021). Of the 88 people who required hospital care 84 (95\%) were inadequately immunised, with just 4 patients receiving one dose at least two weeks before they tested positive (Cheng, 2021). This reflects data on Delta from the United States (Dyer, 2021). Risk modelling from the August 2020 outbreak in Aotearoa calculated that a 55-year-old Pacific person had the same level of risk for hospitalisation as an 80year-old New Zealand European (both without comorbidities) (Steyn et al., 2021). They concluded, "Structural inequities and systemic racism in the healthcare system mean that Māori and Pacific communities face a much greater health burden from COVID-19" (Steyn et al., 2021, p. 28).

Figure 1: Charts show total COVID-19 case numbers by ethnicity comparing August 2021 Delta outbreak with all cases previously recorded in Aotearoa New Zealand (Ministry of Health, 2021b)

\section{Case numbers before 17 Aug 2021. Total 2987}

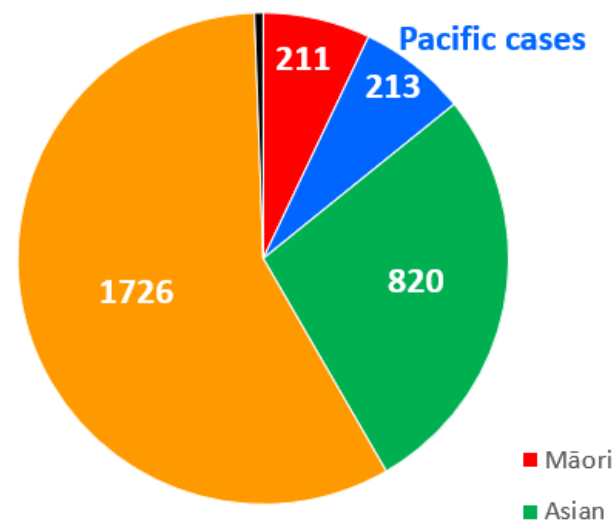

\section{Case numbers from 17 August to 30 Sept} 2021: Delta outbreak. Total 1249

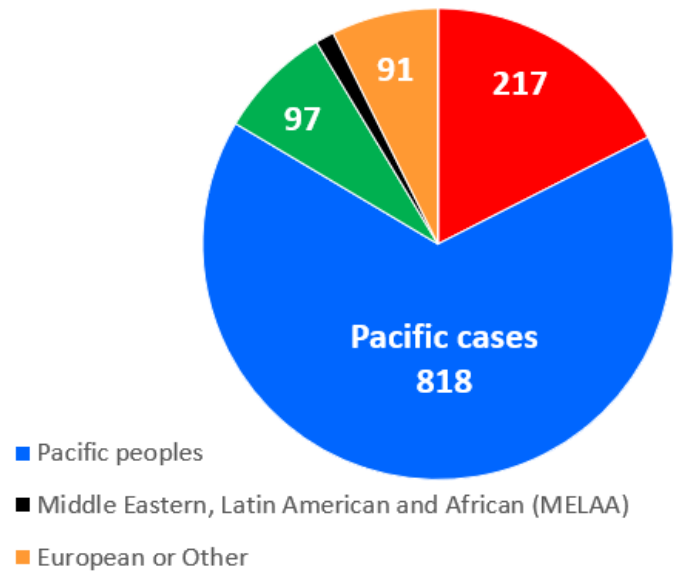

Figure 2: Chart showing vaccination data for one and two doses for the whole of New Zealand and across the three Auckland DHBs comparing non Māori/non Pacific with Pacific

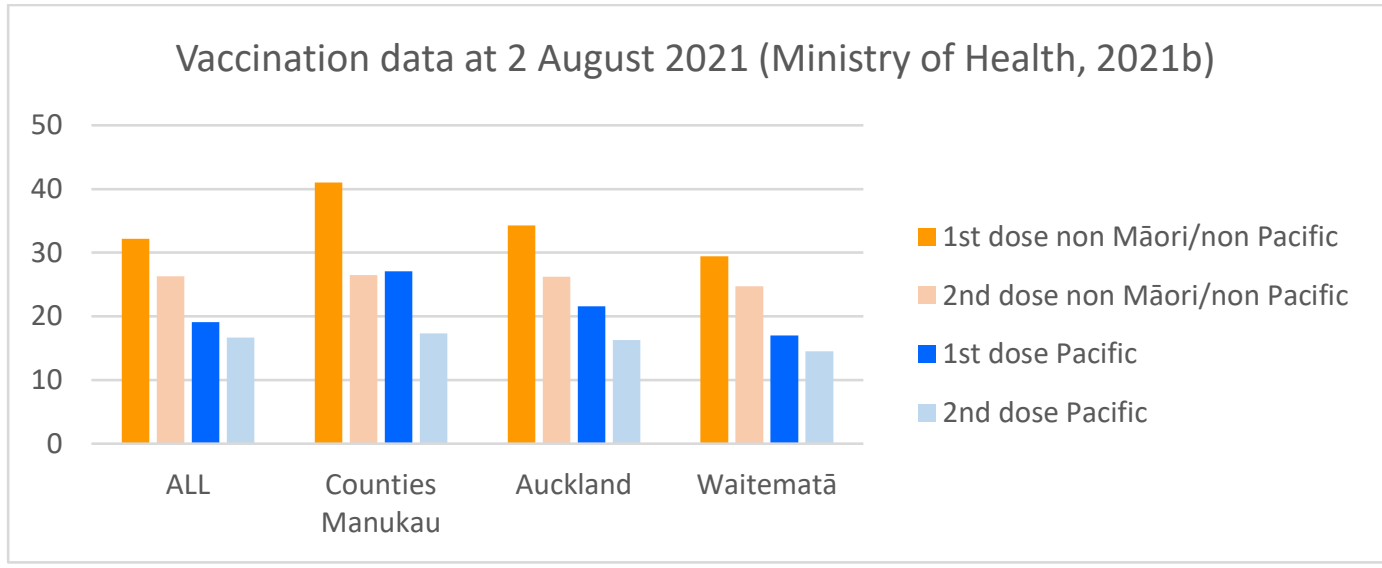




\section{Talanoa: The Conversation}

In this section, our authors, Abel Smith and To'a Fereti, together with Sue Adams, share a conversation, based upon talanoa. Abel and To'a talk from their perspectives as Pacific nurses and leaders, rather than from their organisational positions. Abel is of Fijian descent and has worked as a clinician, educator, and manager in the Fijian, Australian, and Aotearoa New Zealand health care sectors over the last 35 years. He is an Aniva alumni and is currently working on his DHSc at AUT on the Pacific nursing workforce. To'a is Samoan who trained as a nurse in New Zealand. She has held positions as a clinician, educator, and manager in the New Zealand health care sector, and has worked in Samoa and Fiji. To'a is the President of Pan Pacific Nurses Association, an Aniva Alumni, and previous Chair of the Nursing Council of New Zealand. She brings operational, governance, strategic, and leadership to the discussion and is working on a $\mathrm{PhD}$ on Pacific leadership, also at AUT. Sue is a white/European academic and co-leader of the National Enrolled Nurse (EN) and Nurse Practitioner (NP) Workforce Programme, funded through the Ministry of Health. One of the key objectives in this Programme is to support the development of the Pacific nursing workforce, particularly in primary health care and community settings. We held several talanoa (discussions) over Zoom (due to the COVID-19 restrictions), in September and October 2021, transcribed, and then together identified the themes.

\section{History repeats: Resilience and reciprocity}

SUE: History tells us that Pacific peoples have poorer outcomes when infectious diseases spread through communities, such as measles, Strep A sore throats and rheumatic fever, the 'flu pandemic [H1N1] in 2009. How well prepared do you think we were to protect our Pacific communities in a pandemic, particularly for our Pacific nursing workforce?

ABEL: We weren't prepared for the pandemic. We have the capability within the Pacific nursing workforce and experience of working through various pandemics, such as 'flu, measles, strep throat, but we do not have the capacity and have not grown our workforce.

TO'A: The pandemic has made the gaps in workforce highly visible. The current pandemic provides an opportunity for organisations to look at the need to invest in the Pacific workforce. We're needed in a time of crisis, but when that is over, our workforce issues are often forgotten. The pandemic isn't going to go away anytime soon and the worst hit, as always, are Māori and Pacific. This time we have to have a longer-term plan and vision for our workforce.

ABEL: The Pacific nurses though have not had time since the pandemic started, to breathe, refresh refocus, and rebuild, and that's an issue. As nurse leaders, we can foresee the burnout, though I don't think our workforce readily admits to this burnout. Burnout is covert. In Pacific circles we put our community first, our families are everything, and to admit burnout is about us, the individual, and not about our community.

TO'A: I think you are right, Abel. It sits in our heart and our passion for our communities to heed the call and keep going. We may not see this as burnout, we just carry on because we know it is what we need to do for our families and communities.

ABEL: When you ask Pacific students and new nurses, "What do you want to do in your career?" A lot of them state that they want to look after Pacific people, that they want to give back to their community. This is reciprocity and it is about the community's health rather than an individual.

\section{A collective responsibility: Serving the community}

SUE: This pandemic has really highlighted the necessity of a workforce that reflects the population served. We have known for many years the importance of a workforce with cultural and linguistic skills to improve health outcomes for our Pacific communities. Again, through this pandemic, nurses have been central in developing appropriate ways of working with Pacific communities to protect and promote health and showing how they bring joy and love to their work.

TO'A: Pacific nurses are very involved in this pandemic across the sector providing education, testing, contact tracing, working at MIQ facilities, Healthline, vaccination centres, health clinics, supporting families, social needs, and so on. But we haven't done it in isolation, we are and need to be engaging and working with our community because community engagement is the essence of our work. As professionals we don't want to and shouldn't be seen as leading this, but instead the Pacific communities must lead, with us in a supportive role. 
ABEL: For many Pacific nurses, we view nursing as our calling. We come to this pandemic, not as leaders, but as people who serve our community, and in our quest to serve, the pandemic response should be community-led and driven. From what we have seen when the community lead things like a vaccination drive, then the engagement and outcome is very good.

TO'A: The Pacific nurses are front and centre, working closely with our communities. It is their cultural values, their knowledge of the communities and their everyday interactions and connections with our people in hospital, in managed isolation, in clinics and primary care, and in the community, that will help encourage them to engage and be vaccinated.

ABEL: Also, we must remember that Pacific nurses have often been called upon to provide language and cultural support across the sector. This is rarely acknowledged as a strength and asset to organisations. Pacific nurses do this voluntarily and we do it because of our commitment to our community. Using Pacific languages and culturally safe models of communication improves understanding and enables community engagement.

TO'A: Yes, it is so much more than language. It is also around our approach and messaging. If we take the August Delta cluster, we needed to find the most culturally appropriate person to approach our pastors and ministers of religion, to be able to engage with the church community. This was particularly so given the backlash of inappropriate and racist comments, and stories that came through mainstream and social media.

\section{Engagement: A reciprocal partnership approach}

SUE: As you've said, getting the engagement of community Pacific leaders seems to be critical. What have we learnt, as nurses, as the health sector, about how we work with Pacific communities to provide the right information and support their engagement in the pandemic response, such as testing, isolation, and vaccination?

TO'A: The initial engagement is usually from the Pacific providers to the community leaders. It is around making sure that the right people who are trusted and respected are chosen as the spokespeople to go into those Pacific communities, and particularly to engage with the pastors and ministers of the church.
ABEL: What is clear when engaging with Pacific communities is that we, as health care providers and as nurses, need to reconnect with our Pacific values and principles of reciprocity, respect, inclusion, relationships, family, love, spirituality, and use and practice these. When I think about how we are engaging, it is through servant leadership. We need to change the rhetoric and acknowledge that the community has the answers. Many of us are trained in western models of care that operate in parallel with our Pacific models of engagement and health, and we must be mindful of the two different worldviews.

SUE: I'm interested in how nurses navigate their way between the different worldviews of Pacific and the western-European worldview. There were, and still are, myths going around about vaccination. In Samoa, we saw the devastating effects of a measles outbreak in a country with low vaccination rates, a tragic vaccination error, the rise of anti-vaxxers, and then finally strong engagement with leaders to move communities through the fear of vaccination to achieve high vaccination rates. How do nurses manage the tension where community leaders should be the decision-makers for their communities, in say vaccine hesitant communities, while at the same time knowing that being immunised is going to protect their communities? How do nurses reconcile these differences?

ABEL: Too often the health fraternity goes in with the mindset of providing the facts. That is a very simplistic way of changing peoples' views and attitudes, and we know from experience that it hasn't worked. We need to step back and connect to our values and principles. We need to build trust with our communities, promote and support engagement through talanoa that is mana-enhancing [honouring and respectful], gain their confidence, and then through these processes we can give them the opportunity to hear what western science is offering. At the same time there are Pacific worldviews that we need to acknowledge and respect. We work side-byside so people can make informed choices for their families - aiga, kāiga, magafaoa, kōpū tangata, vuvale, fāmili - and their communities. Through this and previous pandemics, here and in the Islands, I've learnt that we've got to step back as nurses and not carry just the agenda of providing facts and demystifying health issues. When I enact my Pacific values of respect, reciprocity, talanoa, and so on, this 
adds a richness to the dialogue that will promote engagement. Somewhere within that dialogue we have an opportunity to peel back the layers to understand how they have reached their views and we can exchange sound scientific knowledge so they can make an informed choice. I've worked with many senior and wise Pacific nurses over the years who do all of this, and they get the engagement and they get the results.

TO'A: And do you think, Abel, it is something that is missing from our curriculum? I think it is missing. Seeing the Pacific nurses who are coming through now, there's a lot to be said for having nursing education in the Islands, because you are constantly working within your cultural norms of reciprocity, of respect, of alofa [love], of what it means to be looking after families and communities, babies right up to our older people. The context of nursing has changed which seems to have impacted on how we embed and integrate our cultural values into our nursing practice. E-technology has changed how we interact with our patients.

ABEL: Nurses refine their practice through postgrad education and practical experience and currently there is a mis-match with our postgraduate curriculum and what's really happening out there in the Pacific world. I've been invited to teach the Pacific context in some postgrad nursing courses and I'm given an hour. I mean what can you teach in an hour - is this tokenism and tick box? We need to find a way of embedding Pacific culture and world views throughout the postgrad curriculum.

\section{The rhetoric of equity}

SUE: How you are talking about language, culture, community engagement, and valuing relationships, seems to me to be at odds with our westernised biomedical model of healthcare and the top-down public health approach that we have mostly seen through this pandemic. How does the model you are talking about fit with the health system's response?

TO'A: The approach nurses use is not biomedical, though we understand the science and the data. It is instead around how we capture the hearts and minds of our communities, because if we can't do that, we don't have a way in at all. So far, the messaging and information has been around the science and data in

1 The Panthers is a New Zealand drama for television set in the 1970s during the period of the Dawn Raids following terms of the virus and the vaccine. Though we have just begun to see this change and we have pivoted into a space where we know we need to engage even more so with our communities, if they are to come and be vaccinated. It is the nurses and their lived experiences and relationships with their communities that is essential. So yes, it is far removed from the biomedical approach.

SUE: There have been several opportunities to do things differently to protect Pacific peoples from the COVID-19 outbreak - at the start of the pandemic; the August 2020 cluster; and now the current [Delta] outbreak, though you have noted a recent shift. In the August 2020 cluster, more young people got COVID19, more Pacific, and more Māori. Yet when it came to the vaccination roll-out [starting May 2021] the oldest age groups were first included and neither Pacific nor Māori were prioritised, despite being a younger group with greater likelihood of poor health outcomes.

TO'A: The pandemic made equity issues more visible. We knew for a long time that Pacific communities were at greater risk, because of the long history of inequities, communities already struggling with poor income, overcrowding, food security issues, generally poorer health. If we had listened to our communities earlier to know how we could do this, particularly with the vaccination roll out, we would have had a way better outcome. Even if we had listened at the start of this Delta [2021] outbreak, it would have been different.

SUE: Our family began watching The Panthers ${ }^{1}$, which was televised about the time the Delta outbreak started. 50 years on and we are still seeing not dissimilar issues of inequity, institutional racism, and overt racism occurring.

TO'A: The Delta outbreak really brought to the fore the biases of our non-Pacific population. The August 2021 cluster started with someone from Devonport [who was non-Pacific/non-Māori] and that person was not slammed [by the media]. Instead, he was praised for going to get tested and doing the right thing. When the cluster spread and reached Pacific churches and Samoan communities, well it was another form of racism. There was blatant racism towards the Pacific communities and the Pacific

the emergence of the Polynesian Panthers. Produced by Halaifonua Finau and Tom Hern. 
nurses. Then everyone was then targeting our Samoan communities.

SUE: That must have been very hard for you as Pacific leaders to witness, knowing that Pacific nurses and their families were both witnessing and on the receiving end of racism.

TO'A: We know there is going to be a very long tail of recovery for our Pacific communities and nurses, and there are going to be ongoing concerns.

ABEL: Yes, I am also worried about the repercussions; about nurses' on-going psycho-social dilemmas, moral injury, their health, and what support will be offered to our nursing workforce post-pandemic? We have had to temporarily put aside some family, church, study commitments. But when the pandemic is over, we will have to pick all this up again, and who is going to support the Pacific nurses.

\section{Experiencing isolation}

SUE: We'll come back to the nursing workforce later. I am interested in how quarantine and isolation have been experienced by Pacific peoples, who are community-oriented, often closely connected to church, and with strong networks of extended family members; and how the nurses have responded. I imagine this was a tension for them.

ABEL: We are a communal people, and in the quest to isolate and quarantine, those processes [MIQ] have not really worked for us. We will need to look at how we serve and engage Pacific peoples better as a collective and look at what works for them and learn from our communities and families as well as from the frontline nurses who have been working in those facilities and areas of support and care.

TO'A: The whole package of MIQ is not only about isolation and quarantine. It is about the activities what you can do in there. It is about the food, welfare, psychological and psychosocial issues of isolation, and mental health. So already when you are starting on a back foot being from a marginalised group, then how does being in isolation [because of testing positive to COVID-19] or quarantine compound health and wellbeing. It is going to be so important that we discover such impacts for the future and how nurses can work in these situations. Also, MIQs are under MBIE [Ministry of Business, Innovation, and Enterprise]. For the nurses this means they have had to interact with various and different agencies which has added another layer of complexity. They have had to overcome different understandings of how they work, their priorities, how they communicate and deliver messages to those in the facilities.

\section{Learnings}

SUE: Thinking about how we capture the learnings from the pandemic for the Pacific nursing workforce, and therefore, the Pacific communities, where do we go from here?

ABEL: As nurses, not only have we served in this pandemic, but it has taken us back to valuing our community development approaches. We need to do research and ensure those studies inform future activities, strategies, policies, and practices. Too often our learning is very short-lived. We are dictated to by systems and structures. As nurses we come to work, we do the work, we just accept how it is, and move on, and we don't question, though I think that is a problem for nursing as a whole.

TO'A: I think this pandemic has also highlighted the short vision of some organisations and employers around diversifying their teams. We need to reflect on how we support Pacific nurses, including how to work with communities, and how we support their ongoing postgraduate education, career development, and cultural competence. We need a targeted roadmap.

ABEL: We know that opportunities to access governance, leadership, and advanced clinical roles for Pacific nurses are lacking - the doors don't open readily just because of the added qualification and experience we may acquire. We need Pacific champions to advocate and carve out pathways, and the lack of Pacific nurses to at the forefront of planning. We need to do things differently in the future. Just like we rely on the Pacific communities to find and lead solutions, we need to use our Pacific nurses to own, plan, and lead their futures.

\section{Policy and practice recommendations}

The burden of the first six weeks of the August 2021 Delta outbreak has fallen heavily on Pacific communities in Auckland, with Pacific nurses stepping up to serve their communities. They have utilised their cultural values, knowledge, and language that has been essential for the protection and wellbeing of their communities. Such work though is not acknowledged and learnings are often short-lived. Embracing Pacific values of reciprocity and collective responsibility has left little chance for 
those nurses to reflect upon and develop workforce strategies, and many are experiencing burnout. From our talanoa and knowledge of the inequities faced, we present the following recommendations in relation to the Pacific nursing workforce.

Firstly, a roadmap for the Pacific nursing workforce is required to not only increase the number of Pacific nurses, but to ensure they have access to career development opportunities, moving into senior positions across the health and tertiary education sectors. While strategies have been published (Ministry of Health, 2020b; Ministry of Health \& La Va, 2012), they have not been adequately resourced and enacted. Just $4 \%$ of the nursing workforce are Pacific (compared to $7.4 \%$ of the population), and of all Pacific nurses only $17 \%$ work in primary health care settings (NCNZ, 2019). There are 8 Pacific NPs out of 534 in total, and very few Pacific nurses in senior leadership positions. This lack of diversity in the health workforce reflects systematic bias and racism within the healthcare system (HQSC, 2021). Organisational commitment at local, regional, and national levels is required to promote career pathways for Pacific nurses, which includes professional and cultural development; postgraduate education; mentoring and peer support networks; and access to colleagues and leaders who will champion Pacific nurses. Increasing the Pacific nursing workforce in primary health care should be prioritised to improve access for Pacific communities to healthcare.

Secondly, Pacific culture and values, knowledge of Pacific ethnicities and communities, and approaches to engage with families and communities to promote health equity, need to be embedded in undergraduate and postgraduate nursing programmes. The Aniva postgraduate leadership programme (Aniva, n.d.), run through Whitireia, is designed to promote Pacific models of care and safety, and leadership knowledge and skills, that support the health and wellbeing of Pacific people in the Aotearoa New Zealand context. Other institutes of technology and polytechnics (ITPs) are running Pacific undergraduate nursing programmes. However, within universities, institutionally racist systems with westernised processes reduce access for Pacific students and academics (Kidman \& Chu, 2019). It is time to forefront Pacific health and wellbeing throughout nursing curricula and to ensure culturally safe processes and practices are in place to engage Pacific students and nurses with tertiary education so they can succeed across the domains of clinical, educational, leadership, and research.

Finally, the health sector needs to acknowledge and learn from the significant role that Pacific nurses have played through the COVID-19 pandemic, and indeed previous pandemics. COVID-19 has further highlighted the gaps in service delivery and inequities for Pacific communities that were already well known (HQSC, 2021; Walsh \& Gray, 2017). Solutions to health issues lie with Pacific communities. We have seen the necessity of ensuring that engagement with Pacific communities is culturally nuanced, and respectful of Pacific worldviews and principles (Ioane, 2021). When this occurs, equity of health outcomes can be achieved. We are hopeful that the health reforms underway will reflect the need for a Pacific nursing workforce that is enabled to work alongside Pacific communities to promote health and wellbeing.

\section{References}

Aniva. (n.d.). Welcome to the Home of Aniva. Pacific Perspectives. https://www.pacificperspectives.co.nz/aniva

Ardern, J. (2021). Speech to Dawn Raids Apology. New Zealand Government.

https://www.beehive.govt.nz/speech/speech-dawnraids-apology

Auckland Council. (n.d.). Pacific Auckland: Who are Pacific people? Author

https://www.aucklandcouncil.govt.nz/plans-projectspolicies-reports-bylaws/our-plans-

strategies/auckland-plan/about-the-aucklandplan/Pages/pacific-auckland.aspx

Auckland District Health Board. (2020). Health needs assessment. Author.

https://www.adhb.health.nz/assets/Documents/Abo ut-Us/Planning-documents/ADHB-Health-NeedsAssessment.pdf

Boodoosingh, R., Olayemi, L. O., Amosa-Lei Sam, F. (2020). COVID-19 vaccines: Getting anti-vaxxers involved in the discussion. World Development, 136, Article no. 105177.

https://doi.org/10.1016/j.worlddev.2020.105177

Cheng, D. (2021, Sept 9). Covid 19 Delta outbreak: How many cases needing hospital care were vaccinated? New Zealand Herald.

https://www.nzherald.co.nz/nz/politics/covid-19-Deltaoutbreak-how-many-cases-needing-hospital-care-werevaccinated/WEI6LAG2HG3KXM4BNK6W2BFM64/

Corlett, E., \& McClure, T. (2021, August 25). New Zealand health chief slams 'gutless' racism against Pasifika people over Covid cluster. The Guardian. https://www.theguardian.com/world/2021/aug/25/ 
concerns-for-new-zealand-pasifika-community-overauckland-church-covid-cluster

Dyer, O. (2021). Covid-19: Unvaccinated face 11 times risk of death from delta variant, CDC data show. $B M J$, 374, n2282. http://dx.doi.org/10.1136/bmj.n2282

Ioane, J., Percival, T., Laban, W., \& Lambie, I. (2021). All-ofcommunity by all-of-government: reaching Pacific people in Aotearoa New Zealand during the COVID-19 pandemic. New Zealand Medical Journal, 134(1533), 96-103.

Evans, M. K. (2020). COVID's color line: Infectious disease, inequity, and racial justice. New England Journal of Medicine, 383, 408-410. https://doi.org/10.1056/NEJMp2019445

Health and Disability System Review. (2020). Health and Disability System Review: Final Report: Pürongo Whakamutunga. Author. https://systemreview.health.govt.nz/final-report/

Isaacs, D. (2020). Lessons from the tragic measles outbreak in Samoa. Journal of Paediatrics \& Child Health, 56, 175-175. https://doiorg.ezproxy.auckland.ac.nz/10.1111/ipc.14752

Kidman, J., \& Chu, C. (2019). 'We're not the hottest ethnicity': Pacific scholars and the cultural politics of New Zealand universities. Globalisation, Societies and Education, 17, 489-499. https://doi.org/10.1080/14767724.2018.1561247

Lees, J., Lee, M., \& Winnard, D. (2021). Demographic Profile: 2018 Census, Population of Counties Manukau. Counties Manukau Health.

https://www.countiesmanukau.health.nz/assets/Abo ut-CMH/Performance-and-planning/healthstatus/Demographic-profile-2018-Census-Populationof-Counties-Manukau.pdf

Health Quality \& Safety Commission. (2021). Bula Sautu A window on quality 2021: Pacific health in the year of COVID-19. Author.

https://www.hqsc.govt.nz/assets/Health-QualityEvaluation/PR/BulaSautu WEB.pdf

Matapo, J., \& Enari, D. (2021). Re-imagining the dialogic spaces of talanoa through Samoan ontoepistemology. Waikato Journal of Education, 26(Special Issue), 79-88. https://doi.org/10.15663/wje.v26i1.770

Ministry for Pacific Peoples. (2021). Impact of COVID-19 lockdown on Pacific churches. Author. https://www.mpp.govt.nz/assets/Reports/MPP Pacifi cPeoplesCOVID2020web.pdf

Ministry of Health. (2017). HISO 10001:2017 Ethnicity Data Protocols. Author.

https://www.health.govt.nz/system/files/documents $\angle$ publications/hiso 100012017 ethnicity data protocols may-21.pdf

Ministry of Health. (2020a). Background and overview of approaches to COVID-19 pandemic control in Aotearoa/New Zealand. Author. https://www.health.govt.nz/system/files/documents/publi cations/background-overview-approaches-covid-19pandemic-contro-aotearoa-new-zealand-30mar20.pdf
Ministry of Health. (2020b). 'Ola Manuia: Pacific Health and Wellbeing Action Plan 2020-2025. Author. https://www.health.govt.nz/publication/ola-manuiapacific-health-and-wellbeing-action-plan-2020-2025

Ministry of Health. (2021a). My DHB. Author. https://www.health.govt.nz/new-zealand-healthsystem/my-dhb

Ministry of Health. (2021b). COVID-19: Data and statistics. Author. https://www.health.govt.nz/ourwork/diseases-and-conditions/covid-19-novelcoronavirus/covid-19-data-and-statistics

Ministry of Health and Le Va. (2012). Taeao o Tautai: Pacific Public Health Workforce Development Implementation Plan. Ministry of Health. https://www.leva.co.nz/wpcontent/uploads/2019/10/taeao-o-tautai-publichealth-workforce-plan.pdf

Nursing Council of New Zealand. (2019). The New Zealand Nursing Workforce: A profile of Nurse Practitioners, Registered Nurses and Enrolled Nurses 2018-2019. Author.

https://www.nursingcouncil.org.nz/Public/Publicatio ns/Workforce Statistics/NCNZ/publicationssection/Workforce statistics.aspx?hkey=3f3f39c4c909-4d1d-b87f-e6270b531145

Sadler, R. (2020, Sept 6). Coronavirus: Locations, ages, ethnicities of New Zealand's 116 active COVID-19 cases. Newshub. https://www.newshub.co.nz/home/newzealand/2020/09/coronavirus-locations-ages-ethnicities-ofnew-zealand-s-116-active-covid-19-cases.html

StatsNZ. (2018). Pacific Peoples ethnic group. Author. https://www.stats.govt.nz/tools/2018-census-ethnicgroup-summaries/pacific-peoples

Steyn, N., Binny, R. N., Hannah, K., Hendy, S. C., James, A., Lustig, A., Ridings, K., Plank, M. J., \& Sporle, A. (2021). Māori and Pacific people in New Zealand have a higher risk of hospitalisation for COVID-19. The New Zealand Medical Journal, 134(1538), 28-43.

Waitematā District Health Board. (2019). Health needs assessment 2019. Author. https://www.waitematadhb.govt.nz/assets/Documen ts/health-needs-assessments/Health-NeedsAssessment-Waitemata-DHB-2019.pdf

Walsh, M., \& Grey, C. (2019). The contribution of avoidable mortality to the life expectancy gap in Maori and Pacific populations in New Zealand: A decomposition analysis. New Zealand Medical Journal, 132(1492), 46-60.

Wilson, N., Barnard, L., \& Summers, J., Shanks, G. D., Baker, M. (2012). Differential mortality rates by ethnicity in 3 influenza pandemics over a century, New Zealand. Emerging Infectious Diseases, 18, 71-77. https://doi.org/10.3201/eid1801.110035

\section{Funding: None}

Conflict of interest: None 